\title{
Carlos Scolari (ed.). Ecología de los medios: entornos, evoluciones e interpretaciones
}

Barcelona: Gedisa, 2015, 297 p. ISBN 978-84-9784-827-5

Carlos Scolari es doctor en lingüística aplicada y lenguajes de la comunicación por la Universidad Católica de Milán; trabaja en la Universidad Pompeu Fabra (Barcelona) y es un reconocido investigador dedicado a la comunicación digital interactiva, a la evolución de los medios y a las narrativas transmedia. En este libro presenta un panorama bien estructurado y a la vez polifónico sobre la ecología de los medios: sus orígenes vinculados con la biología, las discusiones teóricas entre sus principales referentes, su actualidad en el marco de la revolución tecnológica de la comunicación digital interactiva, su relación estrecha con la educación en medios $\mathrm{y}$ sus proyecciones de cara al futuro.

En la introducción, Scolari hace un recorrido cronológico que comienza con los aportes de quienes pueden considerarse los precursores de la ecología de los medios: Lewis Mumford (Technics and civilization, 1934), Jacques Ellul (La technique ou l'enjeu du sciècle, 1954 y Propagandes, 1962), Harold Innis (A history of the Canadian Pacific Railroad, 1923; Empire of communications, 1950, y The bias of communication, 1951) - quien fue el primero en contar la historia de la humanidad poniendo los procesos de comunicación en el centro- y Eric Havelock, considerado el gran experto en la transición de la oralidad a la escritura en la sociedad griega, con su clásico Preface to Plato (1963).

En segundo lugar, Scolari dedica un espacio a los padres fundadores de la ecología de los medios, quienes, a diferencia de los precursores, aplicaron explícitamente la metáfora ecológica a los medios de comunicación. Claramente el primero de ellos es McLuhan, quien ofreció tal vez la metáfora ecológica en su forma más acabada al afirmar que los medios forman un ambiente o entorno sensorial en el que nos movemos como pez en el agua y no nos damos cuenta de su existencia hasta que, por algún motivo, se vuelven visibles. Según McLuhan, los humanos moldeamos los instrumentos de comunicación, pero, al mismo tiempo, ellos nos remodelan sin que seamos conscientes de ello. Las principales obras de McLuhan son: The mechanical bride: folklore of the industrial man (1951), The Gutenberg galaxy: the making of typographic man (1962), Understanding media: the extensions of man (1964), The medium is the massage: an inventory of effects (1967, con Quentin Fiore) y Laws of media: the new science (1988, con Eric McLuhan). Según Scolari, el nuevo contexto que trajo aparejado la revolución digital en las comunicaciones ha dado lugar a un "revival" de las ideas de McLuhan, al punto que la revista Wired, 
en su número inaugural de 1993, lo ungió su "santo patrono". Otro de los padres fundadores es Neil Postman, que al provenir del campo educativo desarrolló una visión ecológica, crítica y ética del sistema mediático estadounidense. Según Postman, la llegada de un nuevo medio no se limita a agregar algo, sino que cambia todo el ecosistema mediático. Algunas obras destacadas de Postman: Amusing ourselves to death: public discourse in the age of show business (1985), Technopoly: the surrender of culture to technology (1992) y The end of education: redefining the value of school (1995). El trío de los padres fundadores se completa con la figura del sacerdote jesuita Walter Ong, quien en su reconocido libro Orality and literacy: the technologizing of the word (1982) analizó los efectos del paso de la cultura oral a la cultura escrita y desarrolló el concepto clave "oralidad secundaria" para dar cuenta de un regreso a la oralidad primaria en virtud de las tecnologías electrónicas. Aunque no aplicó la metáfora ecológica a sus teorizaciones, hay que ponderar en su obra la influencia del propio McLuhan, quien además dirigió su tesis doctoral en la década de 1940.

Es el momento de hablar de los discípulos de la ecología de los medios, entre los cuales Scolari destaca a Lance Strate (primer presidente de la Media Media Ecology Association), Joshua Meyrowitz, Robert Logan (quien estudió junto a McLuhan a finales de los años setenta), Paul Levinson y Derrick de Kerckhove (exdirector del McLuhan Program in Culture \& Technology de la Universidad de Toronto y reconocido actualizador de su obra).

Tal vez uno de los aportes más valiosos del libro es la explicación que el mismo Scolari ofrece sobre la metáfora de la ecología de los medios. Nacida en los años sesenta y setenta en un contexto en el que la ecología - vinculada con la biologíaestaba de moda, la metáfora ecológica admite dos interpretaciones: por un lado, los medios son ambientes. Como dijimos antes, los medios generan ambientes que afectan a los sujetos que las utilizan, y al seguir a McLuhan, esos efectos no se producen a nivel consciente sino que afectan los patrones de percepción sin encontrar resistencia. En segundo lugar, los medios son especies que se relacionan y compiten entre sí. Por ejemplo, Innis analizó el desarrollo paralelo de los ferrocarriles y la telegrafía en el siglo XIX. Postman describió los conflictos entre el telégrafo y la prensa y el papel de la TV en la nueva ecología de los medios. Al respecto, McLuhan afirmó que ningún medio adquiere significado o existencia solo, sino exclusivamente en interacción constante con otros medios. A la primera interpretación Scolari la define como la dimensión ambiental de la ecología de los medios, y a la segunda, la dimensión intermedial, puesto que los medios son especies que viven en el mismo ecosistema y establecen relaciones entre sí.

Sin dudas, otro aspecto destacado de esta compilación que realiza Scolari y que la convierte en una especie de manual obligatorio para aquellos interesados en la ecología de los medios, es precisamente 
la diversidad de autores que reúne en sus páginas. En la primera parte, dedicada a los padres fundadores de la ecología de los medios, se reproduce una extensa entrevista a Marshall McLuhan, publicada en la revista Playboy en marzo de 1969, donde explica - ante un entrevistador inquisidor y escéptico frente a sus provocativas afirmaciones - la mayor parte de sus conceptos. Luego le sigue el discurso pronunciado por Neil Postman durante la inauguración de la Convención de la Media Ecology Association, en Nueva York en junio de 2000, en el que analiza la relación entre la cultura y los medios desde la dimensión ambiental de la metáfora ecológica y - a diferencia de McLuhanasume una postura ética sobre los efectos de los medios. Esta primera parte continúa con un ensayo de Jesús Octavio Elizondo Martínez que profundiza en los orígenes de los estudios sobre los medios en Canadá y Estados Unidos, lo que el autor denomina la Escuela de Toronto, y más particularmente se detiene en las obras de Havelock, Innis y McLuhan y sus influencias recíprocas. La primera parte se cierra con una comunicación de Tom Gencarelli en la que se sostiene que los fundamentos teóricos de la ecología de los medios desarrollados por Neil Postman constituyen la defensa más temprana de la educación en los medios como parte de la instrucción cívica en Estados Unidos.

La segunda parte del libro, titulada "Los discípulos", se abre con un texto de Lance Strate, quien desde el enfoque mcluhaniano propone "estudiar los medios como medios", y es en ese sentido que desglosa en profundidad el clásico aforismo de McLuhan "el medio es el mensaje”. Esta parte del libro continúa con un interesante aporte de Paul Levinson, quien propone una "teoría antropotrópica" según la cual los medios evolucionan hacia una reproducción del mundo pretecnológico, es decir, tienden a la repetición de los patrones de comunicación humana. Luego, Robert Logan aborda la poco estudiada base biológica de la ecología de los medios y profundiza en la extensión de la metáfora ambiental desarrollada por McLuhan al afirmar que la ecología de los medios supone precisamente un estudio de los efectos sociales, culturales y psíquicos de los medios, más allá de su contenido.

La tercera y última parte del libro, dedicada a las nuevas fronteras que se abren para el estudio de la ecología de los medios, reúne tres trabajos muy diferentes entre sí. El primero de ellos, un análisis teórico a cargo de Indrek Ibrus, propone estudiar la evolución de los medios desde la semiótica de la cultura y, tomando distancia de la postura mcluhaniana, propone un abordaje constructivista y multidisciplinar que interprete las dinámicas evolutivas de los medios, particularmente a partir de los aportes de Yuri Lotman y Niklas Luhmann. Luego, Denis Renó alterna el análisis con su experiencia como productor para estudiar el futuro del audiovisual en el contexto de la nueva ecología de los medios que representan la web 2.0 y los dispositivos móviles, especialmente en la manera de producir y relacionarse con los 
contenidos. Finalmente, el libro se cierra con un aporte de Sergio Roncallo Dow y Diego Mazorra en el cual relacionan arte, estética y política, tras hacer blanco en la capacidad que tiene el artista — tal como sostenía McLuhan- de hacer visible el ambiente que crean los medios, aunque ese acto de visibilidad o de toma de conciencia sea escandaloso porque transgrede las normas de la época; y en ese sentido llama la atención el caso del arte transgénico.

\section{Francisco Albarello}

Universidad Austral

falbarello@austral.edu.ar 